\title{
A educação da pessoa com deficiência visual
}

\author{
The education of the visually impaired person
}

La educación de la persona con discapacidad visual

\author{
TÂNIA MARA TRECINO* \\ Universidade do Planalto Catarinense, Lages- SC, Brasil \\ LURDES CARON** \\ Universidade do Planalto Catarinense, Lages- SC, Brasil
}

\begin{abstract}
RESUMO: Este artigo objetiva desenvolver reflexão sobre a educação da pessoa com deficiência visual. Trata-se de pesquisa em fontes bibliográficas e em documentos a partir de autores que refletem sobre a questão. A partir de pesquisa bibliográfica descreve-se a história da educação de pessoa com deficiência visual; a caracterização e o reconhecimento da deficiência visual, bem como o desenvolvimento visual e aprendizagem e os recursos ópticos. Espera-se estar contribuindo para a inclusão escolar e a aprendizagem de deficientes visuais.

Palavras-Chave: Deficiente visual. Educação. Desenvolvimento visual e aprendizagem.
\end{abstract}

\begin{abstract}
This article aims to develop reflection on the education of the visually impaired person. It is an inquiry in bibliographic sources and in documents from authors who reflect on the issue. From bibliographical research, the history of education of a visually impaired person is described; the characterization and recognition of visual impairment, as well as visual development and learning and optical
\end{abstract}

* Mestranda em Educação pela Universidade do Planalto Catarinense. Pedagoga, especialista em Educação Especial e inclusiva. Atua como professora do Atendimento Educacional Especializado das redes municipal e estadual de Lages- SC. E-mail: <taniatrecino@yahoo.com.br>.

** Graduada em Pedagogia pela Faculdade de Filosofia Ciências e Letras do Vale do Itajaí. Mestre em Teologia Prática pela Escola Superior de Teologia e Doutora em Educação pela Pontifícia Universidade Católica de São Paulo. Atua como docente pesquisadora em Educação na Universidade do Planalto Catarinense. E-mail: <lurcaron@gmail.com>. 
resources. It is expected to be contributing to school inclusion and learning for the visually impaired.

Keywords: Visually impaired. Education. Visual development and learning.

RESUMEN: Este artículo tiene como objetivo desarrollar una reflexión sobre la educación de la persona con discapacidad visual. Se trata de una búsqueda en fuentes bibliográficas y en documentos de autores que reflexionan sobre el tema. A partir de la investigación bibliográfica se describe la historia de la educación de personas con discapacidad visual; la caracterización y el reconocimiento de la discapacidad visual, así como el desarrollo visual y el aprendizaje y los recursos ópticos. Se espera que este trabajo contribuya a la inclusión escolar y al aprendizaje de los discapacitados visuales.

Palabras clave: Deficiente visual. Educación. Desarrollo visual y aprendizaje.

\footnotetext{
"Se a educação é para todos de direito natural, ela é para os cegos de direito divino ${ }^{1}$ (GUADET, 1851).
}

\section{História da educação do deficiente visual}

A educação na sua história, normalmente, esteve a serviço dos interesses das sociedades constituídas e, ainda, conforme as necessidades políticas, econômicas e sociais em cada tempo histórico. Os pioneiros na educação das pessoas com deficiência visual, foram jovens estudantes de famílias ricas que, comovidos com a indiferença com que essas pessoas eram tratadas pela sociedade da época, fundaram instituições assistencialistas de caráter caridoso.

Os interesses de caráter educacional em relação às pessoas com deficiência visual surgiram por volta do século XVI, com o médico italiano Girolínia Cardono, que realizou testes de leitura com cegos por meio do tato. Peter Pontamus Fleming (cego) e o padre Lara Terzi escreveram os primeiros livros sobre a educação das pessoas cegas (BRUNO; MOTA, 2001).

Em 1771, o jovem Valentin Hauy estudioso de linguística, se propôs a fazer um trabalho com a educação das pessoas cegas, sensibilizado ao assistir uma apresentação 
sinfônica desafinada de oito cegos, na feira de Santo Ovídio, em Paris, que parecia suscitar o deboche e o riso da plateia. Ele percebeu a forma desrespeitosa com que eram tratados:

Um sentimento bem diferente se apoderou de nossa alma, e concebemos logo a possibilidade de realisar com vantagem para esses infelizes os meios dos quaes eles se serviam aparentemente, e de uma maneira tão ridícula. Então dicemos comnosco mesmo. Não conhece o cégo os objetos pela diversidade de suas formas? Por ventura engana-se ele quanto ao valor de uma moeda? Porque não distinguiria ele um dó de um sol, um $a$ de $\mathrm{um} f$, se podesse apalpar estes caracteres? (GUADET, 1851, p. 09).

Haüy, decidiu então dedicar-se a fundar uma instituição que promovesse a dignidade e a educação das pessoas com cegueira. Iniciou com o jovem François Le Sueur, cego de família pobre que desde criança pedia esmolas à porta de uma igreja até a idade de dezesseis anos, quando o professor Haüy o encontrou. Passou a dedicar seu tempo à adaptação de materiais táteis e à experimentação de várias técnicas de leitura com ojovem Sueur. Seus experimentos foram publicados na sociedade acadêmica, assim, ganhou notoriedade e a sociedade filantrópica de Paris lhe concedeu um auxílio financeiro para a educação de doze jovens cegos. Estava criada, então, a primeira escola para jovens cegos de Paris.

No ano de 1784, Hauy fundou o Instituto Real dos Jovens Cegos em regime de internato, mantido com as doações da Sociedade Filantrópica. Nesse instituto, os cegos manuseavam caracteres com linhas em alto relevo para a leitura de palavras e pequenos textos, que, ainda que favorecesse a adaptação à leitura, não permitia a escrita. Em 1786, publicou um livro explicando seu método: “Teste sobre a educação dos cegos”, , por meio do qual exemplificava suas experiências na leitura tátil.

No ano de 1809, Louis Braille conseguiu uma bolsa de estudos no mesmo instituto, aos 10 anos de idade, pois havia ficado cego aos três anos, vítima de um acidente por um objeto pontiagudo que causou uma infecção no olho e, pouco depois, acometeu o outro olho. Louis dedicou-se avidamente aos estudos, gostava de música clássica, tornou-se um excelente pianista, e mais tarde o talentoso organista de Notre Dame des Champs.

Em 1829, Louis Braille, aluno do Instituto de Cegos de Paris, criou o sistema de leitura e escrita tátil, por meio da utilização de seis pontos em relevo. Louis tomou conhecimento sobre a invenção de Charles Barbier, um oficial de artilharia que passava muito tempo na frente de batalha necessitava escrever e ler mensagens que recebia e enviava durante as noites, utilizando uma lamparina; no entanto isso poderia indicar seu local e expor ao fogo do inimigo. Por isso, Barbier criou um código representado por seis pontos salientes numa folha de papel, para poder se comunicar silenciosamente sem o auxílio da luz, alfabeto que se chamava sonografia. A partir desse modelo inventado por Barbier, Louis adaptou o método para a leitura e escrita tátil, o braille. O Sistema Braille é um marco de grande importância na história da educação do educando com deficiência visual, pois facilitou às pessoas cegas o acesso ao conhecimento. 
No Brasil, em 1854, foi fundada a primeira escola para cegos da América do Sul, pelo então imperador D. Pedro II, denominada de Imperial Instituto dos Meninos Cegos. A iniciativa da criação do instituto foi de um adolescente chamado José Álvares de Azevedo, cego de nascença, inteligente e filho de uma família abastada do Rio de Janeiro. $\mathrm{O}$ jovem foi enviado à França, aos 10 anos de idade, para estudar no Real Instituto de Cegos de Paris. Nessa escola ele teve contato com o Sistema Braille.

Quando voltou ao Brasil, José dedicou-se a divulgar o braille e a lutar pela criação de uma escola como a que havia estudado em Paris. Como fazia parte da Corte, chegou a fazer palestras nas casas de família e nos salões imperiais, escreveu e publicou artigos nos jornais da época, e passou a ministrar aulas para outros cegos, ajudando-os a ler e escrever. Assim, José Álvarez de Azevedo, além de ser o pioneiro a introduzir o braille no Brasil, também foi o primeiro cego a se tornar professor no País.

Foi professor da filha de um notável médico da Corte Imperial, o Dr. Francisco Xavier Sigaud, e por meio dele o jovem professor, Álvares de Azevedo, conseguiu uma audiência com o Imperador D. Pedro II, que ficou impressionado e sensibilizado com a demonstração do Sistema Braille. Assim, em 17 de setembro de 1854, D. Pedro II inaugurou o Instituto de Meninos Cegos na cidade do Rio de Janeiro. Lamentavelmente, o ato de inauguração ocorreu sem a presença do jovem José, que brilhantemente lutou pela educação das pessoas cegas, pois ele faleceu vítima de tuberculose aos 20 anos de idade.

Por sua notória contribuição para a inclusão social das pessoas cegas no Brasil, José Álvares de Azevedo recebeu o título de "Patrono da Educação de Cegos no Brasil", e o dia de seu aniversário, 8 de abril, é declarado oficialmente Dia Nacional do Braille.

Com o movimento da República, a escola mudou a denominação para Instituto dos Meninos Cegos e, tempos depois, Instituto Nacional dos Cegos. O militar, engenheiro e professor Benjamin Constant passou longos anos à frente do Instituto Nacional de Cegos, e quando faleceu, em 1891, foi homenageado pelo governo da recém proclamada República, passando a instituição a se chamar Instituto Benjamin Constant (IBC), que permanece até hoje.

O IBC é atualmente um centro de referência, em nível nacional e internacional, para as questões que envolvem a deficiência visual, além do trabalho de reabilitação das pessoas que perderam a visão ou que apresentam baixa visão. Atua também na capacitação de professores e profissionais de todo o País. Ao longo do tempo, firmou-se como centro de estudos e pesquisas médicas na área da oftalmologia, com programas de residência médica considerado um dos melhores do Brasil. Além de prestar atendimento à população, por meio de exames, consultas e cirurgias em oftalmologia, o instituto é comprometido com a divulgação dos trabalhos acadêmicos, edição e impressão de livros, periódicos e materiais em braille, possuind o um acervo de publicações científicas na área.

Como centro de referência, o IBC passou a realizar atendimentos às pessoas que possuíam algum resíduo visual e, em 1950, foram criadas as Classes de Conservação da 
Visão (CCV) de 1ํa a $4^{\underline{a}}$ séries $^{2}$, nas quais os estudantes com baixa visão aprendiam com professores videntes, utilizando recursos de ampliação, iluminação e contraste de cores, de modo a preservarem o resíduo visual. Também lhes era ensinado o braille, e quando passavam para o ginásio ${ }^{3}$ as turmas ficavam mistas entre baixa visão e cegos.

Em 1926, outras iniciativas de educação para as pessoas com deficiência visual começaram a surgir; em São Paulo foram criados os atendimentos especializados na área da visão, com a Escola Profissional para Cegos, passando mais tarde a chamar-se Instituto Padre Chico, em homenagem ao monsenhor Francisco de Paula Rodrigues. Segundo Mazzota, (2011), para a construção do Instituto de Cegos, no Alto do Ipiranga, o conde José Vicente de Azevedo fez doação de uma grande área de terra. Ainda, segundo Mazzotta (2011), as primeiras atividades nesse Instituto, foram orientadas pelo professor cego Mauro Mantagna, que era professor aposentado do Instituto Benjamin Constant, do Rio de Janeiro. Nesse mesmo ano, surge o Instituto São Rafael, em Belo Horizonte, Minas Gerais, e em 1933, em Salvador, na Bahia, o Instituto de Cegos da Bahia. Os princípios básicos dessas instituições eram a educação básica, a formação profissional e a integração do cego na sociedade.

Foi em São Paulo, na década de 50, que iniciaram as primeiras tentativas de inclusão de estudantes com deficiência visual no ensino regular. Também no Rio de Janeiro e na Bahia, foram criadas escolas de referência na visão, como a Escola Estadual Getúlio Vargas e o ICEIA.

No ano de 1946, foi criada a Fundação para o Livro do Cego no Brasil (FLCB), com o objetivo principal de produzir livros e materiais em braille. Fundada pela educadora Dorina de Gouvea Nowil, que ficou cega aos 17 anos, vítima de uma infecção ocular. Preocupada com a educação e a inclusão das pessoas com deficiência visual na sociedade, ela conseguiu convencer a direção da escola Caetano de Campos, onde cursava o magistério, a criar o primeiro curso de especialização de professores para o ensino de cegos. Os livros em braile eram raríssimos e ao formar-se professora Dorina viajou para os Estados Unidos para participar de um curso de especialização na área da deficiência visual, na Universidade de Colúmbia, com a intenção de trazer novos materiais para o País.

Quando retornou ao Brasil, dedicou-se à produção de livros em braille, criando uma editora que hoje produz mais de $80 \%$ dos livros do Ministério da Educação para os deficientes visuais. Em 1961, Dorina foi responsável pela criação do Departamento de Educação Especial para Cegos em São Paulo. Além de lutar para a implantação de leis que assegurassem o direito a educação das pessoas com deficiência visual, participou da criação do primeiro órgão nacional de educação de cegos no Brasil, em Brasília pelo Ministério da Educação. Em 1979 foi eleita presidente do Conselho Mundial dos Cegos, e da Fundação para o Livro do Cego no Brasil, criada por ela, e que passou a ser denominada Fundação Dorina Nowil em sua homenagem. 
Hoje, novas tecnologias acompanham os avanços na educação e alfabetização da pessoa com deficiência visual; esses recursos viabilizam possibilidades reais de inclusão, por meio de softwares, ledores de comando de voz, mouse óptico, sensores de leitura através dos dedos, teclado ampliado, teclado em braile, entre outros.

Na década de 1970, a educação especial ganhou notoriedade pelos movimentos em defesa dos direitos das minorias. Nessa perspectiva, em 1975, a Assembleia Geral da Organização das Nações Unidas (ONU) proclamou a Declaração dos Direitos das Pessoas Deficientes. Dentre os direitos assegurados, no Artigo 6º sobre a educação, destaca:

As pessoas deficientes têm direito a tratamento médico, psicológico e funcional, incluindo-se aí aparelhos protéticos e ortóticos, à reabilitação médica e social, educação, treinamento vocacional e reabilitação, assistência, aconselhamento, serviços de colocação e outros serviços que lhes possibilitem o máximo desenvolvimento de sua capacidade e habilidades e que acelerem o processo de sua integração social (BRASIL, 1975, p. 02).

Em 1971, a Lei no 5.692, que fixou as Diretrizes e Bases do Ensino de $1^{\underline{0}}$ e $2^{\underline{0}}$ grau, assegurava: “[...] tratamento especial para os alunos que apresentem deficiências físicas ou mentais, os que se encontrem em atraso considerável quanto à idade regular de matrícula e os superdotados (BRASIL, 1971)". Percebemos a intenção do atendimento especializado, no entanto, a Lei ainda não regulamentava como se daria a integração dos estudantes com deficiências no ensino regular.

Com o objetivo de promover a expansão e melhoria do atendimento aos "excepcionais ${ }^{4 \prime}$ em todo território nacional, foi criado, pelo Ministério da Educação, o Centro Nacional de Educação Especial (Cenesp), por meio do Decreto nํ72.425, no ano de 1973. Em Santa Catarina, no ano de 1977, a FCEE, juntamente com o Cenesp, elaborou e executou um projeto de implantação das classes especiais nas escolas de ensino regular, com o objetivo geral de: "[...] atender alunos deficientes mentais educáveis em classes especiais nos estabelecimentos da rede oficial de ensino (FCEE, S/D)". Para os estudantes com deficiências sensoriais foram criadas as salas de multimeios, posteriormente denominadas como salas de recursos multifuncionais.

Em 1985, o Decreto Presidencial no 91.872, propôs a transformação do Centro Nacional de Educação Especial (Cenesp) em Secretaria de Educação Especial (Sesp); entre mudanças políticas e sociais, em 1992 a sigla passou a ser Seesp, com a mesma denominação. Em Santa Catarina, a Secretaria de Estado da Educação (SED), "em 1987, constatou que aproximadamente 200.000 crianças em idade escolar não tinham acesso à escola”. Assim, a SED, percebendo o grande número de crianças sem acesso à escola, "desencadeou o estabelecimento do Plano de Ação da SED para o quadriênio 1988-1991”, com o objetivo de garantir a escolarização básica para todas as crianças (SC/SED, 2006, p. 12). Nesse plano estabeleceu cinco diretrizes para o atendimento dos educandos com deficiência: 


\begin{abstract}
Acesso ao ensino regular de educandos com deficiência, assegurado pela matrícula compulsória; Permanência mediante a expansão das modalidades alternativas de atendimento (salas de recursos, salas de apoio pedagógico e salas de atendimento alternativo para deficientes mentais nas localidades onde não houvesse escolas especiais); Descentralização administrativa com a implementação das equipes regionais de educação especial; Reorganização curricular para a elaboração da proposta curricular do Estado; Pesquisa e extensão para a capacitação de educadores e desenvolvimento de ajudas técnicas (SANTA CATARINA -SED/FCEE, 2006, p. 13).
\end{abstract}

Na década de 90, novos paradigmas começaram a serem traçados com vistas à garantia de direitos e respeito à diversidade e cidadania das pessoas com deficiência, resultando em movimentos sociais para a inclusão, evidenciados na Conferência Mundial sobre Educação para Todos, realizada na Tailândia em 1990. Nessa Declaração, os países assumem um novo compromisso com a educação: "a educação é um direito fundamental de todos, mulheres e homens, de todas as idades, no mundo inteiro" (BRASIL, 2004a, p. 15).

Com o movimento da luta em defesa dos direitos humanos, em 1994, em Salamanca, na Espanha, foi realizada a Conferência Mundial sobre Necessidades Educativas Especiais: Acesso e Qualidade, cuja principal diretriz estava voltada aos princípios, política e prática da educação especial.

No ano de 2003, o MEC implanta o Programa Educação Inclusiva: direito à diversidade, com vistas à transformação dos sistemas educacionais em sistemas educacionais inclusivos, promovendo a formação de gestores e educadores nos municípios brasileiros para "assegurar aos alunos que apresentem necessidades educacionais especiais, as condições para ter acesso e permanência na escola, desenvolvendo as suas potencialidades em todos os níveis, etapas e modalidades da educação, na perspectiva de construir uma educação inclusiva" (BRASIL, MEC - SEE, 2005, p. 21).

Nos marcos político-legais da educação especial na perspectiva da educação inclusiva, é publicado, em 2004, o documento O Acesso de Alunos com Deficiência às Escolas e Classes Comuns da Rede Regular, com o objetivo de "disseminar os conceitos e diretrizes mundiais para a inclusão, reafirmando o direito e os benefícios da escolarização de alunos com e sem deficiência nas turmas comuns do ensino regular (BRASIL, 2005, p. 15).

Esse mesmo documento traz a promulgação do Decreto № 6.949, de 25 de agosto de 2009, da Convenção Internacional sobre os Direitos das Pessoas com Deficiência e seu Protocolo Facultativo, assinados em Nova York, em 30 de março de 2007, onde o Brasil se propõe a executar e cumprir todas as recomendações para promover e proteger os direitos e a dignidade das pessoas com deficiência.

O estado de Santa Catarina conta com o Serviço de Reabilitação Visual e Adaptação de Prótese Ocular da Fundação Catarinense de Educação Especial (FCEE), que funciona no campus da Instituição, em São José, na grande Florianópolis e, desde 2017, atende pessoas encaminhadas pelo Sistema Único de Saúde, por meio de convênio com a Secretaria de Estado da Saúde (SES). O serviço é desenvolvido por uma equipe multidisciplinar de 
profissionais especializados, como oftalmologistas, especialistas em baixa visão, optometrista, assistente social, psicólogo e professores especialistas em reabilitação visual, avaliação funcional da visão e orientação e mobilidade ${ }^{5}$.

\section{Caracterização da deficiência visual}

A definição dos conceitos na deficiência visual apresenta diferentes denominações, dessa forma percebemos as dificuldades de comunicação entre os profissionais, estudantes e os serviços de reabilitação da visão. A utilização de uma linguagem única permitiria a universalização do atendimento, nortearia os estudos e o levantamento de dados em variadas regiões do País.

A pessoa com deficiência visual é aquela que tem baixa visão ou é cega. Segundo Bruno (2009, p. 35 ) a partir da avaliação funcional da visão do ponto de vista educacional, ) pessoas cegas, são as que apresentam "desde ausência total de visão até a perda da projeção de luz", cujo processo de aprendizagem se fará por meio da integração dos sentidos: tátil- sinestésico- auditivo-olfativo-gustativo, utilizando o Sistema Braille como principal meio de leitura e escrita.

Ainda segundo Bruno, (2009, p. 34), pessoas com baixa visão são as que apresentam "desde condições de indicar projeção de luz até o grau em que a redução da acuidade visual interfere ou limita seu desempenho". O processo educativo se desenvolverá por meios visuais, ainda que seja necessária a utilização de recursos específicos.

De acordo com o documento Programa de Capacitação de Recursos Humanos do Ensino Fundamental: deficiência visual MEC/SEESP (2001), considera-se baixa visão ou visão subnormal a alteração da capacidade funcional da visão, decorrente de inúmeros fatores isolados ou associados, tais como: baixa acuidade visual significativa, redução importante do campo visual, dificuldades de adaptação à luz e ao escuro e para a percepção de cores, alterações corticais e/ou de sensibilidade aos contrastes que interferem ou limitam o desempenho individual da pessoa.

$\mathrm{Na}$ abordagem educacional, a verificação de que estudantes com o mesmo grau de acuidade apresentam diferentes níveis de desempenho visual nos mostra que os estudos de Bruno (2009) enfatizam a necessidade de uma avaliação funcional da visão, pela observação mais abrangente que contemplasse, além do funcionamento visual, os aspectos pedagógicos.

Nessa perspectiva, a avaliação funcional da visão passou a configurar como o estudo do desempenho visual do estudante em todas as atividades diárias; para Bruno (2009) essa avaliação revela dados qualitativos de observação informal sobreo nível de desenvolvimento visual do estudante; o uso funcional da visão residual para atividades educacionais, de vida diária, orientação e mobilidade; a necessidade de adaptação à luz e aos contrastes; a adaptação de recursos ópticos, não-ópticos e equipamentos de tecnologia. 
É importante destacar que a avaliação funcional da visão deve ser realizada o mais cedo possível, para que a criança possa ter condições para o desenvolvimento humano e consequentemente um melhor desempenho visual. Essa avaliação é feita pelo médico oftalmologista, que orienta do ponto de vista clínico o professor especialista na deficiência visual, que fará a avaliação no contexto educacional.

Da mesma forma, a relevância da avaliação é destacada pelo Programa de Capacitação de Professores na Deficiência Visual, do Ministério da Educação:

A avaliação funcional realizada pelo pedagogo especializado é de fundamental importância para o diagnóstico e conduta oftalmológica porque, além de conter dados de observação do desempenho visual da criança em termos práticos e qualitativos, informa o nível de desenvolvimento global e principalmente, como a criança utiliza a visão residual para integração com as pessoas e com o mundo que a cerca (BRUNO; MOTA, 2009, p. 54).

Avaliar estudantes com deficiência visual, principalmente aqueles que possuem baixa visão, é uma tarefa que exige competência técnica: para compreender o processo de interação, de comunicação, das habilidades, das dificuldades para aprendizagem, considerando as necessidades educacionais específicas desses estudantes.

\section{Reconhecimento da deficiência visual na escola}

Identificar os estudantes com deficiência visual nas escolas nem sempre é uma tarefa fácil, principalmente na baixa visão, pois os próprios estudantes muitas vezes omitem informações para serem "iguais" aos demais colegas. Não que a diferença na acuidade visual possa lhes trazer incapacitações, mas no sentido de se sentirem aceitos. Sendo assim, cabe ao professor a sensibilidade e o olhar aguçado sobre os alunos; para isso, a formação continuada é de grande valia, pois oportuniza espaços de troca de experiências, de formação técnica para a utilização dos recursos ópticos e de construção de saberes inclusivos.

A cegueira é mais fácil de ser percebida em relação à baixa visão e em geral é detectada mais cedo; esse diagnóstico, quanto mais precoce for, pode ser determinante no desenvolvimento global da criança. Ao começar na educação infantil, a observação é elemento importante para a identificação das dificuldades visuais. É no espaço da sala de aula que os professores podem observar sintomas, posturas, comportamentos e necessidades da criança, que podem ser indicativos de alguma deficiência na visão, sendo necessário o encaminhamento ao médico oftalmologista e ao atendimento educacional especializado (AEE).

Dentre os sinais, os mais comuns são: dores de cabeça, fechamento dos olhos para visualização, tonturas, sensibilidade à luz, franzimento da testa, piscar continuadamente, visão dupla e/ou embaçada, lacrimejamento, dor e lacrimejamento nos olhos. 
Quanto ao comportamento do estudante com deficiência visual, podemos perceber que levanta várias vezes da cadeira, apresenta dificuldade para distinguir cores, inclinação do corpo sobre a mesa durante a leitura, aperta e esfrega os olhos, dificuldade para seguimento de objetos, desatenção, falta de interesse, inquietação, irritabilidade, dificuldade para ler e escrever, dificuldades para escrever dentro dos espaços da pauta do caderno, entre outros.

Esses sintomas e comportamentos podem ser mal interpretados pelos professores por desconhecimento sobre a deficiência visual. O estudante pode ser considerado preguiçoso ou desinteressado, quando de fato não consegue ter uma qualidade visual que possibilite realizar as atividades escolares.

Muitas vezes o estudante somente apresenta um erro de refração, que pode ser corrigido facilmente com óculos prescritos pelo médico oftalmologista; no entanto, o estudante com baixa visão precisará de outros recursos ópticos para a aprendizagem, pois o uso de óculos não corrigirá a dificuldade visual.

\title{
Desenvolvimento visual e aprendizagem
}

A chegada de um estudante com deficiência visual na escola pode ocasionar preocupações dos professores e gerar angústia. Acolhê-lo com carinho e atenção são os primeiros passos para o planejamento das atividades escolares. Para Gasparetto (2010, p. 347):

\begin{abstract}
a baixa visão gera preocupações e desafios aos educadores que buscam obter o melhor desempenho visual dos alunos com baixa visão por meio do uso de recursos de tecnologia assistiva, sejam eles ópticos, não ópticos e educacionais, de modo a melhorar o desempenho visual na escola e fora dela.
\end{abstract}

A baixa visão exige adaptações e recursos que auxiliem o estudante no processo do ensino e da aprendizagem, ao mesmo tempo que estimulem o uso funcional do resíduo visual. Para Otalara et al., 2008, p. 217, “No mercado brasileiro, as tecnologias assistivas para deficientes visuais são insuficientes para atender as reais necessidades dessas pessoas". O Brasil ainda tem muito a aprimorar. Segundo Otalara et al. (2008), dos recursos que tem disponível para deficientes visuais, como máquinas de braille, regletes, bengalas, lupas e softwares são recursos na maioria não desenvolvidos no Brasil e de alto custo para a aquisição.

Além da ausência de recursos didáticos para trabalhar com deficientes visuais, outra dificuldade é a ausência de formação de professores. Assim, na formação continuada, os professores precisam conhecer todos os recursos que podem melhorar o desempenho no cotidiano escolar de todos os estudantes, inclusive os com deficiência visual.

No decreto nํ⒌296 de 2004, que estabelece as normas e critérios para a acessibilidades, encontramos o termo "ajudas técnicas" designadas como 
produtos, instrumentos, equipamentos ou tecnologia adaptados ou especialmente projetados para melhorar a funcionalidade da pessoa portadora de deficiência com mobilidade reduzida, favorecendo a autonomia pessoal, total ou assistida (BRASIL, 2004).

Nesse grupo de ajudas técnicas, estão os auxílios para a baixa visão, classificados como recursos ópticos e recursos não ópticos e eletrônicos. Além desses recursos, há a necessidade de adaptações no currículo, adequações metodológicas e didáticas. Portanto, é necessária uma mudança no trabalho pedagógico, na busca de proporcionar o desenvolvimento da aprendizagem do estudante com deficiência visual.

\section{Considerações finais}

Muitos são os desafios e compromissos de todos os envolvidos nas questões da deficiência visual, e há necessidade de ampliar conhecimentos e ações que possibilitem às pessoas com essa deficiência o acesso ao saber.

No mercado brasileiro, as tecnologias assistivas para deficientes visuais, ainda hoje, são insuficientes para atender as necessidades das pessoas com deficiência visual. Para o trabalho pedagógico no cotidiano da sala de aula, objetivando a inclusão de deficientes visuais, é de suma importância investir em políticas públicas para a efetiva formação de professores.

Nosso desejo é contribuir para o ensino e a aprendizagem do estudante com deficiência visual, garantindo os recursos e adaptações necessárias para o desenvolvimento da sua aprendizagem. Esse papel é de todos: governo, família, escola e sociedade.

Aceito em: 13/02/2019 e Aprovado em: 25/11/2019

\section{Notas}

1 Foram mantidos os termos gramaticais do autor.

2 Termo utilizado na época para referir-se ao ensino por séries.

3 Idem.

4 Termo utilizado na época para referir-se às pessoas com deficiência intelectual.

5 http://www.sc.gov.br/index.php/noticias/temas/saude/servico-de-reabilitacao-visual-da-fundacao-catarinense-de-educacao-especial-volta-a-atender-pacientes-do-sus. Acesso em 20/02/2019. 


\section{Referências}

INSTITUTO BENJAMIN CONSTANT/MEC. Divisão de Pesquisa. Documentação e Informação, v.1, n.1, Rio de Janeiro: DDI, 1995. Disponível em: <http://www.ibc.gov.br/images/conteudo/revistas/benjamin_ constant/2016/edicao-especial-05-novembro/bc-ed-especial2016.pdf.> Acesso em 03 de set. de 2018.

BRASIL. Declaração dos Direitos das Pessoas Deficientes. Resolução aprovada pela Assembleia Geral da Organização das Nações Unidas - ONU, em 09/12/75. Disponível em: <http://portal.mec.gov.br/seesp/ arquivos/pdf/dec_def.pdf $\geq$. Acesso em: 12 de out. de 2018.

. Lei 5.692 de 11 de agosto de 1971. Fixa Diretrizes e Bases para o ensino de $1^{\circ}$ e $2^{\circ}$ graus, e dá outras providências. Disponível em: http://www2.camara.leg.br/legin/fed/lei/1970-1979/lei-5692-11agosto-1971-357752-publicacaooriginal-1-pl.html. Acesso em 10 de outubro de 2018.

. Lei Ordinária no 4394 de 20 de novembro de 1969. Dispõe sobre o Sistema Estadual de Ensino de Santa Catarina. Disponível em: http://leisestaduais.com.br/sc/lei-ordinaria-n-4394-1969-santacatarina-dispoe-sobre-o-sistema-estadual-de-ensino-de-santa-catarina. Acesso em: 24 de setembro de 2018.

. Ministério da Educação, SEE - Secretaria de Educação Especial. Educação Inclusiva: direito à diversidade. Brasília, 2005. Disponível em: <http://portal.mec.gov.br/seesp/arquivos/pdf/orientador1.pdf. Acesso em 13 de set. de 2018>.

. Ministério da Educação. Secretaria de Educação Especial. Educação inclusiva: v. 1: a

fundamentação filosófica. Brasília: Ministério da Educação, Secretaria de Educação Especial, 2004.

. Ministério da Educação. Secretaria de Educação Especial. Marcos Político - Legais da

Educação Especial na Perspectiva da Educação Inclusiva/ Secretaria de Educação Especial. - Brasília:

Secretaria de Educação Especial, 2010.

BRUNO, M.M.G.; MOTA, M.G.B. Programa de Capacitação de Recursos Humanos do Ensino

Fundamental: deficiência visual vol. 1 fascículos I - II - III. Brasília, DF: Ministério da Educação,

Secretaria de Educação Especial, 2001.

BRUNO, Marilda M. G. Avaliação educacional de alunos com Baixa Visão e Múltipla deficiência na Educação infantil. Dourados, MS: Editora UFGD, 2009.

FCEE. FUNDAÇÃO CATARINENSE DE EDUCAÇÃO ESPECIAL. História da Educação Especial. Disponível em: <http://www.fcee.sc.gov.br/index.php/institucional/sobre-a-fcee/historia\#d-eacute-cadade-1970-e-os-movimentos-internacionais $\geq$. Acesso em: 13 de set. de 2018.

MANTOAN, Maria Teresa Eglér (Org.). O desafio das diferenças nas escolas. Petrópolis, RJ: Vozes, 2008.

GASPARETTO, M. E. R. F. Orientações ao Professor e à Comunidade Escolar referentes ao Aluno com Baixa Visão. In: SAMPAIO, M. W. et al. (Org.). Baixa visão e cegueira: os caminhos para a reabilitação, a educação e a inclusão. Rio de Janeiro: Cultura Médica, Guanabara Koogan, 2010, p.347-360.

MAZZOTTA, Marcos, J. S. Educação Especial no Brasil: história e políticas públicas. 6 ed. São Paulo: Cortez, 2011.

GUADET, J. O Instituto dos Meninos Cegos de Paris, sua História e seu Methodo de Ensino. Tradução de José Álvares de Azevedo. Acervo Digital da Biblioteca Nacional do Rio de Janeiro. Typographia de F. de Paula Brito. Rio de Janeiro:1851.<Http://objdigital.bn.br/objdigital2/acervo_digital/div_obrasgerais/ drg1464351/drg1464351.html\#page/2/mode/1up $\geq$. Acesso em: 13 de set. de 2018. 
INSTITUT NATIONAL DES JEUNES AVEUGLES. Histoire - Valentin Haüy. 1745-1822. Disponível em: $<$ http://www.inja.fr/Default/valentin-hauy.aspx>. Acesso em 03 de set. de 2018.

OTALARA, Picoli Aline, LOPES, Deisy Piedade Munhoz, STEIN-BARANA, e MORENO, Leandro Xavier. PROVER: Tecnologias assistivas voltadas para pessoas cegas ou com baixa visão subnormal - entre o que se espera e o que se encontra, 2008, p. 217-234.. IN: ALMEIDA, Maria Amélia, MENDES, Encéia Gonçalves e HAYASHI, Maria Cristina Piumbato Innocentini. Temas de Educação Especial: deficiências sensórias e deficiência mental. Araraquara - SP: Junqueira\&Marin; Brasília - DF: CAPES PROESP, 2008.

SANTA CATARINA. Secretaria de Estado da Educação. Fundação Catarinense de Educação Especial. Política de Educação Especial do Estado de Santa Catarina: Coordenador Sergio Otavio Bassetti São José: FCEE, 2006. Disponível em: file:///C:/Users/Tania/Downloads/Pol\%C3\%ADtica\%20de\%20 Educa\%C3\%A7\%C3\%A3o\%20Especial.pdf. Acesso em: 02 de out. de 2018.

SANTA CATARINA. O Serviço de Reabilitação Visual e Adaptação de Prótese Ocular da Fundação Catarinense de Educação Especial (FCEE). 31 de julho de 2017 atualizado em 01 de agosto de 2017. http://www.sc.gov.br/index.php/noticias/temas/saude/servico-de-reabilitacao-visual-da-fundacaocatarinense-de-educacao-especial-volta-a-atender-pacientes-do-sus. Acesso em 20/02/2019.

TOMÉ, Dolores. A infocomunicação em harmonia com a musicografia braille: proposta de plataforma digital inclusiva. Tese (Programa Doutoral de Informação e comunicação em Plataformas Digitais) Faculdade de Letras Universidade do Porto. Portugal, 2016. 